\title{
More Than Meets the Eye: How Black and Minority Ethnic Care-Leavers Construct and Make Sense of Their Identity
}

\author{
Isabelle Lensvelt ${ }^{1}$, Alexander Hassett ${ }^{2, *(D)}$ and Alicia Colbridge ${ }^{3}$ \\ 1 Children and Young People's Directorate, Oxleas NHS Foundation Trust, London SE18 3RZ, UK \\ 2 School of Psychology and Life Sciences, Canterbury Christ Church University, Tunbridge Wells TN1 2YG, UK \\ 3 Family Safeguarding Team, Hertfordshire Partnership University NHS Foundation Trust, \\ Stevenage SG1 2ST, UK \\ * Correspondence: alex.hassett@canterbury.ac.uk; Tel.: +44-1227-92-7093
}

Received: 28 October 2020; Accepted: 11 January 2021; Published: 27 January 2021

\begin{abstract}
Looked-after children are exposed to significant developmental trauma which may impact their identity development. Discourses of vulnerability and maladaptation often surround this group, while care-leavers often self-identify as survivors. The role of culture in identity formation is also well documented, and cultural socialisation is linked to psychological adjustment and wellbeing. Despite this, little research has explored identity development in black and minority ethnic (BAME) care-leavers. Interpretative Phenomenological Analysis is used to analyse eight semi-structured interviews with BAME care-leavers about their experience of identity development. Three superordinate themes were developed: My journey-how I became me; Identity as a process - the processes that support identity development; and who am I—how I see myself now. Participants' identity development was adaptive in the context of surviving significant disruption and trauma. Findings are discussed with reference to previous research and limitations are considered. Clinical implications include the need to address additional barriers to positive self-identity faced by BAME care leavers, the importance of acknowledging care-leaver identity as adaptive and embodying a trauma-informed approach to working with this group. Further research into how care-leavers experience their cultural identity is needed.
\end{abstract}

Keywords: care-leaver; identity development; BAME; culture; developmental trauma

\section{Introduction}

\subsection{Identity Development}

Identity is widely thought to be essential to wellbeing and mental health, and an ambiguous or negative self-identity has been linked to a number of psychiatric diagnoses [1]. Despite considerable research into 'identity', it remains a hard-to-define concept [2]. Most definitions of identity emphasize a sense of self and belonging, which begins to develop in childhood and shows continuity over time. This paper adopts the following definition from The Framework for the Assessment of Children in Need and their Families [3]:

[Identity is] the child's growing sense of self as a separate and valued person. It includes the child's view of self and abilities, self-image and self-esteem, and having a positive sense of individuality. Race, religion, age, gender, sexuality and disability may all contribute to this. Feelings of belonging and acceptance by family, peer group and wider society, including other culture groups. (p. 19) 
Attachment theory [4] proposed that the ability of a care-giver to respond appropriately to their baby's needs significantly shaped the baby's identity development. While acknowledging the importance of early relationships, Erikson [5] suggested that identity development continues from infancy throughout the lifespan. His lifespan developmental model highlighted eight different life stages, each of which involves navigating a particular psychosocial task or crisis. Erikson's model suggested that during adolescence, the key crisis is one of identity vs role confusion; the process of reflecting on and integrating previous identifications into a unique and authentic sense of self. Marcia [6] expanded on Erikson's work to suggest that adolescents who successfully navigated this task achieved 'identity commitment', whereas those who did not were left in a state of 'identity diffusion', unable to find a continuous sense of self. Moving away from a stages model, McAdams' [7] narrative identity suggested that identity is constructed through the stories we build as our lives unfold. In keeping with Erikson's model, late adolescence was considered a key time for starting to pull, together this narrative, which continues to grow and adapt throughout the lifespan. Narrative identity is thought to be shaped not just by personal stories, but the interaction between self-constructed stories, those shared with others, and societal and discursive influences [8]. Alternatively, rather than one, fixed story of the self, literature has begun to explore the idea that we all have a plurality of identities [9]; multiple, concurrent identities which are tempered by our current relational and cultural context. These are all adaptive and integrated aspects of the self, which allow us to navigate the social world. Contemporary research has also refuted the idea that adolescence is the most crucial period for identity development. Arnett [10] argued that following adolescence, it was unlikely for individuals to have made a commitment to their identity. He suggested a period of 'emerging adulthood', occurring in between Erikson's stages of adolescence and young adulthood, in which exploration would intensify as the young person moves towards the stability of adult commitments.

\subsection{Looked-After Children and Identity}

The Children Act (1989) defines looked-after children (LAC) as children 'for whom a court has granted a care order to place them in care, or for whom a council's children's services department has cared for more than 24 hours'. LAC are frequently exposed to significant developmental trauma such as abuse or neglect [11]. Childhood trauma can have a major impact on identity formation, including the delaying of maturation and pathological identity formation [12]. It can equally result in post-traumatic growth, and the development of a 'survivor' self-narrative [13]. Stigmatisation of the foster care and LAC labels may also have a detrimental impact on identity development [14]. Nurcombe-Thorne et al. [15] found that the lack of autonomy experienced in care diminished young peoples' sense of self. Furthermore, Stein [16] found that failure by carers to help LAC understand their background can have a negative impact on identity development. 'Promoting positive identity' is one of the key outcomes in the Care Standards Act's (2000) National Minimum Standards. Despite this, there is limited empirical literature exploring the experience of identity development for LAC.

While it is necessary to understand the difficulties faced by care leavers, discourses of "vulnerability" and "maladaptation" appear to be dominant in academia and the media [17]. Care-leavers themselves tend to self-identify as "survivors", sharing alternative narratives of resilience and strength [18]. This could fit with a narrative identity conceptualisation. If someone is able to re-story difficult experiences with a sense of meaning-making and redemption, this may facilitate the strengthening of a positive self-identity [7]. It is important to capture the stories that care-leavers themselves share about their lives and identities.

\subsection{Cultural, Ethnic Identity and BAME Children in Care}

The role of culture in identity formation is well documented. Ethnic and Racial Identity (ERI) development involves a process of cultural socialization and exploration, through which a commitment to a particular ethnic group is made [19]. Literature focuses on the role of parents in providing this socialization, for example introducing children to cultural traditions and preparing children for the 
biases they will experience because of their ethnicity [20]. Evidence suggests cultural socialisation and ERI commitment are linked to psychological adjustment and wellbeing [21]. There is emerging evidence that peer relationships may also play an important role in this process [19].

In the UK, BAME children are over-represented in foster care [22]. In addition, there are fewer foster placements with BAME carers than BAME children in need of foster care. BAME children are more likely to be placed in residential care than their white counterparts, and tend to experience worse outcomes [23]. BAME LAC may miss opportunities for cultural socialisation with their families, and are at additional risk of psychosocial and relational difficulties compounded by ethnic and cultural differences in placements [24]. Further, they may be at greater risk of internalised racism or feelings of difference and not belonging [25] than white children in care. However, evidence suggests that when cultural identity development is considered and supported sensitively, children in trans-racial care can achieve good outcomes [26]. Having knowledge of and access to one's own cultural heritage is linked to better outcomes for adopted and looked after children and is a key factor in the development of a coherent sense of self [27]. It is vital not only to understand the experiential impact on identity of growing up in care, but also how this intersects with identifying with a BAME group.

\subsection{Rationale for Research}

BAME care leavers tend to experience worse outcomes then their white counterparts and may face additional barriers to positive identity development. Given the apparent centrality of identity to wellbeing, it is important to develop an understanding of how BAME care-leavers construct and experience their identity, and the factors that inhibit or promote positive self-identity. Despite this, there is sparse research into the identity development experiences of BAME care-leavers. Through expanding the literature in this area, mental health services and social care will be better placed to support this group of young people.

Identity development research in LAC tends to involve children or adolescents. Recent evidence suggests that identity development may continue throughout young adulthood [28]. This study will therefore recruit young adults, in the expectation that they may be further along in their identity development.

\subsection{Aims of Research}

To develop an insight into some of the ways that BAME care leavers make sense of who they are and the experiences that shaped their identity.

\subsection{Research Questions}

a. How do BAME care leavers construct and make sense of who they are?

b. How do BAME care leavers understand their experiences of being in care?

c. How do BAME care leavers relate these experiences to their sense of who they are?

\section{Method}

\subsection{Design}

Interviews were analysed using Interpretative Phenomenological Analysis (IPA). IPA is underpinned by a social constructionist epistemology, which purports that knowledge is co-constructed by people through the agreed use of language and the shared meanings ascribed to it [24]. Dominant discourses around minority groups and care leavers tend to be constructed about these groups rather than by them. They are often created from a Western cultural viewpoint by those in positions of power, such as government and media. This study is interested in the meaning and understanding that BAME care leavers make of their own experiences. 


\subsection{Participants}

In total, eight BAME care-leavers took part in the study: four were women and four were men (Table 1). All participants had experienced instability and trauma as children, living in multiple contexts in and outside of care. Inclusion criteria were: 18 to 25 years old, from a BAME background, non-British born parents, significant period in care (minimum 6 months); and fluent in English. Exclusion criteria were: adopted children, brief period in care (e.g., days/weeks); kinship care; learning disability; experiencing significant emotional distress, to the extent that participation may be harmful.

Table 1. Participant demographic information.

\begin{tabular}{ccccc}
\hline Pseudonym & $\begin{array}{c}\text { Age } \\
\text { (Age into Care) }\end{array}$ & Ethnicity & $\begin{array}{c}\text { Current Contact } \\
\text { with Birth Family }\end{array}$ & $\begin{array}{c}\text { Reason Entered Care } \\
\text { (Participant Report) }\end{array}$ \\
\hline Agata & $24(14)$ & Black African & None & Unaccompanied asylum seeker \\
Jack & $21(1)$ & Black British & None & Not disclosed \\
Irfan & $25(15)$ & Arab & Yes & Unaccompanied asylum seeker \\
Nina & $23(11)$ & Asian British & Yes & Domestic violence/parental \\
mental health/death of parent \\
Claire & $21(14)$ & Black British & Limited & Parental mental health/neglect \\
Marco & $24(16)$ & Black British & Sister & Parental abuse \\
Naomi & $21(15)$ & Black African & None & Unaccompanied asylum seeker \\
Aiden & $24(15)$ & Arab & None & Unaccompanied asylum seeker \\
\hline
\end{tabular}

\subsection{Recruitment}

Participants were recruited through a charity for care-leavers. Key workers at the charity discussed the research with care-leavers and obtained consent to be contacted by the researcher from those who expressed interest. The researcher and participant met at the charity. Initial discussions covered confidentiality, highlighted potential negative consequences (e.g., distressing topics raised), and emphasised the participant's right to stop or withdraw at any time.

\subsection{Ethical Approval}

Ethical approval was obtained from Salomons Institute for Applied Psychology's Ethics Committee at Canterbury Christ Church University (V: $\backslash 075 \backslash$ Ethics $\backslash 2017-18)$. The study adhered to the British Psychological Society's [29] code of ethics and conduct. Participants' distress and risk issues were considered throughout the interviews, and participants were offered advice on accessing support post-interview.

\subsection{Interviews}

Existing literature was considered when developing the semi-structured interview schedule. The second and third authors had undertaken related research previously [18], and their interview schedule served as a guide. A panel of care-leavers were consulted during project development. Their comments and reflections shaped the final questions (Table 2). Through incorporating feedback and existing theory and research, it was felt that the resulting interview schedule encouraged a wide and in-depth conversation about past, present and future experiences of identity and identity development (see Table 2 for list of interview questions). As the study was interested in subjective experiences of identity, the authors attempted to limit preconceptions or expectations of what aspects of identity were being explored. The interview schedule served as a guide only, with the interviewer following the narrative brought by the interviewee. Interviews lasted between 54 and $99 \mathrm{~min}$, with participants deciding where to end. Participants were provided with a space to debrief after the interview. Participants were offered GBP 10 reimbursement for their time and travel costs. Interviews were digitally recorded, transcribed, and anonymized for analysis. 
Table 2. Interview schedule.

\begin{tabular}{|c|c|c|c|}
\hline 1. & I wondered if you could start by telling me a bit & 7. & How do you think others see you? \\
\hline 2. & It would be helpful if you gave me a brief timeline of & & $\begin{array}{l}\text { Are there things about you that most people } \\
\text { don't know? }\end{array}$ \\
\hline & $\begin{array}{l}\text { your lite, so I have a sense of your journey to date. } \\
\text { Could you tell me a bit about your path into care? }\end{array}$ & 9 & What influences have helped shape who you are? \\
\hline 3. & How would you describe yourself as a person? & 10. & You mentioned $\mathrm{x}, \mathrm{y}$ and $\mathrm{z}$ as important aspects of who \\
\hline 4. & How do you feel about yourself? & & ad these? \\
\hline 5. & What makes you unique? & & How has who you are changed over your life? \\
\hline 6. & How you see yourself in relation to others? & 12. & yourself in the future? \\
\hline
\end{tabular}

\subsection{Data Analysis}

Analysis followed the procedure for IPA as outlined by Smith and Osborn [30]. The transcripts were read several times to gain familiarity with and immersion in the data. In each reading, aspects of the dialogue that stood out were commented upon, increasing the likelihood that themes developed came from the text itself and not from the assumptions of the researcher [31]. The transcripts were re-read, and comments were organised into preliminary themes. These themes were continually reviewed with reference to the transcript and quotes were identified for each theme to ensure they captured the participant's experiences. Similar themes were grouped and refined to form new subthemes. Related subthemes were then clustered together into superordinate themes. Once this process was completed for one participant, the same procedure was applied to the next transcript. Once all transcripts were read and analysed individually, themes were compared across the data set. Themes were reviewed and refined with reference back to the transcripts, to ensure they captured the experience of each participant. All final sub- and superordinate themes were organised into a structured table.

\subsection{Quality Assurance}

Yardley's [32] quality assurance guidelines were followed throughout the research process. The research was grounded in existing literature [33]. Using a reflective diary and having a bracketing interview [33] allowed for reflection and reflexivity. Smith and Osborn's [30] guidelines for conducting IPA were adhered to, to ensure methodological rigor. During analysis, the second author provided inter-coder comparison [32] on a sample of transcripts, to ensure that themes were grounded in the data. Transparency [32] was ensured by clearly detailing the data collection and analysis, and through provision of an audit trail of theme development. Themes were also evidenced with quotes from the data.

\section{Results}

Analysis resulted in the construction of three superordinate themes comprising eleven subordinate themes. The superordinate themes were "My Journey: How I became me", "Who am I? How I see myself now" and "Identity as a process: Processes that support identity development".

\subsection{My Journey: How I Became Me}

This superordinate theme encapsulated memories and past experiences which played a significant role in shaping participants' identities including 'overcoming adversity', 'missing childhood', 'construction of family' and 'pivotal moments'. While participants had very different life experiences, and made sense of them in different ways, each participant spoke of the past and its impact on them growing up and in the present. 


\subsection{Overcoming Adversity}

The adversity participants faced and overcame in childhood was an important part of their story. All participants felt a lack of control and agency in their adverse childhood experiences. As children, they felt unable to change their circumstances, only survive them. As Aiden reflected:

Try to forget it. Cos you can't do anything can you? You have to live with it. So try and put it out your mind, but it was always there. It was always back in there. (Aiden)

Furthermore, participants felt let down by the adults who were perceived to have more agency to create change, but were either unable or unwilling to do so. This contributed to a feeling of others as untrustworthy, uncaring or ineffective.

I thought she had good intentions at first, but I feel like after a while I got to see that it was just an act. (Jack)

\subsection{Missing Childhood}

Another shared aspect of participants' journeys was that of a missing childhood. As young adults, participants looked back at their childhoods with loss and mourning, and a sense of protective anger for their younger selves. Some participants felt this in the unwanted responsibility they found themselves carrying as children.

So I never had a childhood. You think that when you grow up at the time you will have toys, and stuff, I never had that. I was working. (Aiden)

Linked to this was a need for participants to grow up fast and learn to protect themselves. There was an overwhelming experience of aloneness in participants' pasts, which forced them to leave behind the vulnerability and dependency of childhood for self-reliance.

It's like they would spend their money stupidly because it's like they could ask them [parents] for a favour like you are payback or something. I can't do that. (Aiden)

This missing childhood meant that participants had often not had the same opportunities to play, learn and grow as other young children. For some participants, this manifested in the absence of certain life skills:

Before that I didn't even know how to cook, didn't know how to clean, didn't know how to do my hair, still don't now know how to do my hair. But yeah just the natural learnings that you will get when you're growing up from your parents. (Claire)

For others, it was more felt in a sense of being eternally childlike:

I'm always going to be a child, there's always going to be a fantasy world in my head, that's not going to change. When I'm growing old, I'm still going to be a child. (Nina)

This left participants holding conflicting identities as mature children, but immature adults, contributing to a fragmented, hidden self.

\subsection{Constructing Family}

This subtheme related to the ways in which participants appeared to experience and construct the concept of 'family'. Participants spoke of their evolving sense of what family meant for them. Some privileged the importance of blood-ties in constructing family, while others shared an evolving sense of family to include foster families, and later, friends. 
And I also have my biological dad but we don't talk about him. We can talk about him, but, I don't mind talking about him, but I wouldn't class him as family. (Marco)

I know now that I wasn't treated the way I was supposed to be treated, if it was my mum and dad erm or my family blood. (Naomi)

For a number of participants, shared cultural and ethnic background had been an important part of their idea of family, as expressed by Nina below:

I've always felt that when you're a Bengali, when you're from, with the Bengali's, it's a really nice culture, it's really, really nice, when you're in that family, it's a family. (Nina)

Participants discussed the influential roles that birth and foster family and friends played in their identity development. For all participants it seemed clear that their experience of family had significantly contributed to the world views and values they came to hold.

My foster mum, she's been just a mum, and she showed me what is the love of a mum. (Agata)

Further, what was central to the experience of family was a sense of ambivalence towards relationships. Participants shared mixed, conflictual feelings and beliefs about birth family, foster carers, social workers and friends. There was a sense of conflict in that participants appeared to both desire closeness and recoil from it. In some cases, participants were aware of this conflict, as aptly expressed by Nina:

My sister was my weakness but she was also my strength, my sister can actually drive me crazy, like, being away from her made me crazy and being with her made me crazy too. (Nina)

However, there also appeared to be times where participants were unaware of some of the contradiction inherent in their experience of relationships:

[About a foster carer] Mm she's a good woman. I'm not going to lie. She, she a, she was a good woman

... Every now and then I think "how did you make it to be a foster carer?" (Naomi)

This ambivalence about closeness appeared to relate to a need to hide the most vulnerable aspects of the self, to protect them against harm or rejection from others.

I had to hide behind different masks and personas, if you like, so I wasn't being myself, I was just trying to hide my weak side, my vulnerable side. (Irfan)

\subsection{Pivotal Moments}

All participants reflected on pivotal moments in their lives, both negative and positive, which led to a significant shift in the way they saw themselves or others. For some, there were key relationships that had been instrumental in strengthening alternative narratives of others as trustworthy, and the self as worthy; people who had "gone the extra mile".

Once I had, I was, I was out. I had no money. I called [foster carer] and I asked for money. And she gave me the money from her pocket. Cos they usually give me money for the week from social services, she gave money from her pocket, she don't have to do it, she done it. That was really something ... I always remember. (Aiden)

There were also key times when adverse experiences in relationships drove participants to choose a different path to those who abused or let them down.

I don't think I'm Christian the way I used to be. Cos even the pastor, he was on their side, accusing me and everything. So after that, it was like, "no, you don't serve god in a truthful way". So um. That kind of like had an impact [on religious beliefs]. (Naomi) 
There were also examples of key moments, which seemed like turning points in participants' lives. Both positive and negative experiences, these led to personal shifts in outlook, or changes in circumstances.

When I was travelling, when I was in the lorry, I was kind of like very unhappy. I was like, "why am I doing this?" "I bet I die". But I was like, I will, I told myself "I'll make this different". I gave myself a time, I said by the time I'm 30 I will have everything I need. (Aiden)

That was probably like, the happiest day of my life, you know, it was something big; and from then on it was, you know, life started to become a lot better. (Irfan)

\subsection{Identity as a Process}

This superordinate theme captures the adaptive psychological processes observed by the researcher within the interviews, which appeared to support participants in the development and protection of their identity within the aversive contexts discussed above. This included 'defence mechanisms', 'searching for belonging' and 'sense-making'.

\subsection{Survival/Defence Mechanisms}

All participants utilised conscious survival strategies and unconscious defences to see them through their childhoods. While these survival mechanisms had some unwanted relational consequences, they were highly adaptive given participants' adverse contexts. Participants were reflective about the nature and function of a number of conscious intra- and interpersonal processes, as well as their consequences. These included distancing from others and focusing on the positives.

I probably just blocked out by trying to be so humorous all the time. Because then people would find it very hard to just guess that I'm just in care. They'll be very shocked like "what, really? You're in care?" (Irfan)

I don't take anything to heart. I don't take anything to heart. Don't let nothing to affect me in a negative way. Yeah that's me. (Naomi)

There were also unconscious processes which, while not identified explicitly by participants, appeared to serve a defensive function for the self. The prominence of the researcher's interpretations in drawing out these processes, in particular drawing on psychoanalytic theory, is acknowledged; however, it was felt they contributed to a richer understanding of the participants' stories and as such warranted inclusion. Defences included splitting, denial and intellectualising.

They really helped me because here is a charity organisation, people are not fake here, they're doing it with their heart, they're not going to get money from me, that much, as much as the foster carers were getting; being in foster care was not nice because everybody was doing it for the money. (Nina)

The first 7 years of my life [in Jamaica] was bliss. I was spoilt rotten as a child ... I cannot remember what it was like in Jamaica. I think I completely blocked it. (Marco)

\subsection{Search for Belonging}

The search for belonging appeared to span participants' life narratives. For all participants this was an ongoing, active process. It appeared to link somewhat with the aloneness discussed in the 'Missing Childhood' theme, and perhaps developed as a process to try and overcome this aloneness.

I didn't feel comfortable coming out to socialise with the family, because she always made me feel I was outside of the family, even though I was there living in the household. (Jack)

For many participants struggling to find their place in the world, identifying with others of a similar ethnic or cultural background provided a powerful sense of belonging. 
So yeah it was nice to have the fact that we are from the same culture and that. I could have been placed with any, no disrespect it could have been a white family. Which is not really relatable to me. (Jack)

The charity had become, for most participants, a place where they found some sense of belonging and consistent care.

They have been very, very supportive. They have always sort of been there. They help me get into employment, onto my apprenticeship, and they always help me try to get back into education. It just felt like someone cares. (Claire)

Participants continued their search for belonging as they looked to the future, considering parenthood as a way to find their place.

I don't want to be, even if I have my own family I don't want my kids, I don't want to be like 60 and my kids to leave me alone, like, I want them to be around me (Aiden)

I'm going to be one of those single parents with my adopted kids. (Marco)

\subsection{Sense-Making}

A constant meaning-making process was apparent throughout the interviews. It appeared to be a bi-directional process, of understanding the present through the lens of the past and making sense of the past through experiences in the present. For some participants, making sense of their experiences seemed to lead to self-compassion; letting go of some responsibility for their difficulties.

I've realised that with people, because I know a lot of people who had abusive relationships, they end up attracting those. I ended up attracting someone who was like my dad. So, for some reason, maybe because I was missing him, but in a different context, in a different relationship. So, I wanted some elements of my dad. (Nina)

For others, there was a sense of acknowledgment and appreciation for how the past had forged their personality.

I get my personality and where I come from. I know why am so animated, and I know I'm so hyperactive. Being bullied at home, being bullied at school, my way of navigating that was literally by acting my way through it. Oh, you're going to bully me? I'm still a boss though, I'm going to pretend to be happy. (Marco)

Some participants also appeared to enter into this process of sense-making during the interview.

[Addressing the researcher after she asked a question] Do you think you'd be able to answer it? What thing made you that? ... Yeah, the journey, here, everything. Back in home, everything. Everything put me in the place where I'm at. I'm nothing now, but still, the place I am now. And I appreciate it a lot. (Aiden)

\subsection{Who Am I? How I See Myself Now}

This superordinate theme focused on how participants appeared to understand and relate to their identity now. While acknowledging the individuality and diversity within the sample, a number of facets of identity appeared to particularly resonate with participants, being 'survivors', 'different', 'helping others' and experiencing 'bicultural identity and acculturation'. 


\subsection{Am a Survivor}

Participants shared their experiences from the perspective of having survived them. Their incredible adaptability and resilience enabled them to overcome their childhood adversity and work towards desired futures. Participants saw their experiences as having made them stronger.

So yeah, it was tough, but that makes me strong and make me realise to do what I have to do, just to survive. (Agata)

Well it made me stronger. Because before I let him get away with it. Because I wanted a family, boyfriend. Didn't want to do single mum thing and everything so I let it go. (Naomi)

Their survivor identities also came with a drive for a better future, and a belief they could overcome any obstacles that arose.

But this year I got my stay now, so I feel like nothing's going to stop me. There's no excuse and I have to do it. (Naomi)

I didn't have a direction where I was going to go in life or what I wanted out of life. Education wasn't going too well ... I just felt lost. So I decided to take every opportunity that came my way. (Claire)

\subsection{Am Different}

Each participant spoke of how their experiences made them different from other people. This had some negative connotations, such as feeling like an outsider and not having support to fall back on, but also reflected participants' views of themselves as more responsible and driven than others. A number of participants felt their peers were more carefree than them, because they had families to fall back on.

I feel like I'm sensible, because they have parents to back them up the certain things that I don't. (Irfan)

I have English friends who have grown up here, who were born, who don't know the pressure of things like I do, and they don't work hard as much as I do. Cos they know, back in at the end of the day, they have somewhere to go. (Aiden)

They also believed others who had not been through what they had could not understand them fully, and so did not like to share their past. At times this extended to a fear of being stigmatised by others.

Being in care I feel like there has been a lot of negatives towards being labelled as a foster child or relieving care child or whatever. Because I feel like people's first thought is when I think of that is older probably mentally damaged, or something like that (Jack)

Feelings of difference were also compounded by issues relating to racial profiling and discrimination.

I'll never forget Sarah went, "If I saw you, the black guy in an alleyway I would be scared". And everyone just laughed, and me and Amy just looked at each other like "are you serious?" (Marco)

Even I was trying to change my name cos as soon as they see my name or my seen where I'm from, I believe they will try to ignore, they will try to not give the job to this race of people. (Aiden)

\subsection{Helping Others}

Most participants connected with the role of being a helper or carer of others. In discussing existing relationships, participants noted how they often became someone who looked after people or organised them, provided a listening ear or even physical care. 
I try to support anyone. Even if I don't know the person I will try to help (Irfan)

I love to help people. I don't have much but I try to do what I can do. (Naomi)

Aspirations for the future also often included being able to help others, either indirectly by means such as giving money to charity, or by working in helping professions.

I am definitely going to open a residential home for special needs, because, special needs, if the parents are not around, where do they go? They're going to end up in a care home, and I'm not going to let that happen. (Nina)

I'm always thinking of my future to be ... being helpful to other people, even, I don't know, donate some money to charities or that kind of thing. (Aiden)

\subsection{Bicultural Identity and Acculturation}

All participants touched on their cultural backgrounds, and how they had integrated their culture into their identity. Participants appeared to forge their own path while navigating culture, selectively adopting aspects of the culture, and adapting cultural traditions to fit in with their personal values and identity.

Cos the Congolese love fashion, they love mixing colours, colourful colours and stuff. They like to be seen as unique. I think that's what, I think I relate to that. And the music, yeah the music is more me. The fun stuff. (Naomi)

I'm proud to be Jamaican, I wasn't for a long time, but I like embrace my Jamaican culture. But I class myself as British because when I have conversations with people that are literally fresh off the boat, we have two very different mind-sets. (Marco)

A number of participants also described feeling disconnected from or forgetting aspects of their culture. This was particularly felt by participants who were refugees unable to return to their country of origin.

My culture. To be honest, what is my culture? I've kind of lost most of my culture. (Agata)

It goes goes goes goes the longer I'm out of my country. So you've kind of forgotten everything, you've forgotten how the people used to act back in the home. You've kind of forgotten everything about the culture, what people used to do, I'm a part of this country now. (Aiden)

\section{Discussion}

Explicit consideration of the role of ethnicity and culture on care experiences varied between participants and, as reflected by the emergent themes, appeared more present in some areas of conversation and less in others. Participants described a number of formative experiences that may resonate with LAC and care-leavers regardless of cultural and ethnic background. However, almost all participants disclosed experiencing additional hardship as a direct result of their ethnic backgrounds, whether due to language barriers, cultural taboos or direct experiences of racism. Furthermore, implicit suggestion of struggles relating to ethnic disparities appeared to permeate throughout the interviews. For example, Clare's description of missing opportunities to learn how to style her Afro-Caribbean hair highlighted a painful absence of ethnic socialization which may not have posed an issue for her white counterparts in care. It is important to acknowledge the visible whiteness of the interviewer, and the potential barrier this presented to participants feeling able to bring particular aspects of their identities into the conversation.

The influence of interpersonal trauma on later development, in particular the development of pathology, is well documented [34]. In keeping with this, the results suggest that participants' early 
adverse experiences were significant in identity development. Participants were reflective about how their early experiences shaped them and were aware of some of the narratives of pathology and maladaptation about care-leavers. However, they saw their identity development as adaptive, and saw themselves as resourceful survivors. In keeping with narrative identity [7], this suggests that participants had found ways to incorporate redemption and meaning-making into their stories of early adversity. In addition, rather than solely defining their identities by their early experiences, identity development for participants appeared to be an ongoing process of self-definition and discovery. This fits with Erikson's [5] assertion that identity development continues over the lifespan.

A key aspect of participants' identity was being different. There was a sense that participants' early experiences made them outsiders, and meant others would struggle to understand them. This is commensurate with much of the previous LAC literature [35], however this study expanded on these findings in that participants' feelings of difference as LAC appeared to be compounded by an awareness of their visible differences as minorities. The concept of intersectionality [36] is useful when considering the interplay of these characteristics. Embedded in participants' narratives were multiple, concurrent experiences of oppression and exclusion due to race, in addition to LAC status, gender, sexuality and religion. One Black Caribbean participant felt that white foster carers had unintentionally encouraged his internalised racism. Another felt that he was disadvantaged in job applications due to having a Muslim name. In beginning to explore the interaction of these multiple experiences of oppression, this study builds upon the previously mentioned LAC research to highlight the need for an intersectional approach to exploring BAME LAC identity.

The feeling of difference experienced tied in with a sense of a 'hidden self' throughout the narratives; aspects of participants' identities that they did not share. Kools [14] similarly found that LAC did not present their 'real' selves to others, particularly their most vulnerable selves. However, rather than an attempt to mask the "real" self, the present study builds on the findings of Colbridge, Hassett and Sisley [18] that suggest the hidden self was an adaptive and integrated part of participants' identities, which allowed them to survive in numerous challenging environments. This may also support the notion of the existence of multiple, concurrent identities. As suggested by Barn [9], participants' skilfully navigated their different identities, including LAC and BAME identities, in their search for belonging.

All participants spoke of their experience of engaging with their culture. In keeping with ERI theory [21] they valued opportunities to connect with their family's culture, whether with family themselves, or through the attempts of carers to seek out appropriate cultural activities. However, all participants appeared determined to develop a cultural identity that fitted with their own experience, rather than conform to existing cultural frameworks. This fits with the concept of 'biculturalism'; the selective integration of aspects of both one's background culture and the dominant culture in the current setting [37]. The current findings suggest that, even in situations where participants were suddenly and permanently removed from their cultural context, they find adaptive and identity-congruent ways to make sense of their cultural identities in their new context.

Responsibility was a key concept in the identity of most participants. This tended to manifest in identifying with helper or caring roles, often meaning that participants' own needs were left unacknowledged. By taking up a helper role, participants may defend against identifying with their own unmet need for care. This could be understood psychoanalytically as a defence against vulnerability, projecting this into others or developing a reaction formation of invulnerability in themselves [38]. Similarly, Heller and LaPierre [39] suggested that child victims of abuse or neglect may associate having needs with being bad. This could lead to the adoption of a helper role to defend against the shame of acknowledging one's own needs, as well as vulnerability.

Throughout the interviews, participants were engaged with the researcher in an active process of introspection and sense-making. This lends itself to a social constructionist perspective; both the participants' inner dialogue, and the dialogue with the researcher, were part of the meaning-making process [40]. Building on McLean's [8] narrative identity work, this highlighted the relational and 
socio-cultural influence on the life story. The sense-making process also highlighted the confusion and contradiction participants still face. This was perhaps a manifestation of participant's fragmented memories and identities. In psychoanalytic theory, fragmentation can be understood as the result of repressing internal experiences that threaten the relationship with the primary caregiver, leading to unconscious conflict [41]. Similarly, betrayal trauma theory [42] suggests that when children are abused or neglected by a primary care-giver, their survival relies on maintaining the relationship, so they may be forced to forget or disconnect from the feelings of betrayal elicited by the abuse.

This may also link to participants' search for belonging, which was characterised by conflict and ambivalence. While belongingness is considered a fundamental human motivation [39], the need for safety precludes the need for belongingness [43]. As participants' archetypal relationships were unsafe, ambivalence towards relationships may have been necessary for their safety [44]. Heller and LaPierre [39] suggest ambivalence, in the context of unsafe relationships, is understandable given the child's desperate need for and intense fear of others.

Most participants spoke of a sense of safety, care and belonging within the recruitment charity. Despite the significant relational trauma in participants' backgrounds, they had come to see the charity as a sort of 'secure base' [2]. This speaks to the personal growth of participants in taking the risks needed to forge this relationship, as well as the dedication, warmth and compassion of the charity workers.

This highlights the reparative potential of relationships in relational childhood trauma. All participants shared exceptional experiences of genuine warmth, care and love from others, which provided an alternative blueprint for relationships, and for constructing their identity. This again is suggestive of identity development as a life-long, dynamic, relational process [5]. The aspirations for closeness and financial stability shared by participants also communicated their own belief in the potential for change and growth.

\subsection{Limitations}

Participants comprised a group of care-leavers seeking employment opportunities at a charity with whom they had been able to develop strong relationships. They were willing and able to tolerate talking to a stranger, in depth, about personal and painful experiences. As such, it is likely that there was a recruitment bias towards people who were, to a greater or lesser extent, coping in life, and had begun to process and integrate some of their trauma. All participants had London-based foster placements. Particularly when considering cultural identity, young BAME people in less diverse areas may have different care experience.

IPA requires a homogenous sample so that findings remain contextualised within the parameters of the study [45]. Although attempts were made to recruit a homogenous sample, the sample was made of mixed-gendered participants with a variety of trauma and care backgrounds, with differing birthplaces and ethnicities.

A further limitation is the small sample size. However, Interpretive Phenomenological Analysis (IPA) has a focus on data richness, so small samples are advocated for IPA research $[30,46]$ to achieve rich phenomenological insight. IPA is an established qualitative methodology developed by Smith and his colleagues $[30,47]$ and used extensively in psychological research. Jonathon Smith, who invented IPA, provides a useful discussion about numbers of participants in his article [46]. Data saturation is never an objective in an IPA research. Several authors [48-51] emphasise that in qualitative research a focus on the quality of research results/contributions is more important than the quantity. Although some forms of qualitative data analysis use inter-rater reliability (IRR) to establish the reliability of the coding this needs to be in line with the epistemological stance of the research. A review by McDonald et al. [52] indicates that only one in nine studies use some form of IRR. In this research and in line with accepted steps in IPA, during the analysis, the second author provided inter-coder comparison $[32,53]$ on a sample of transcripts, to ensure that themes were grounded in the data. Where there was variation in ideas about the theme, the researchers returned to the data to co-construct the theme. 
Another limitation lies in the unavoidable influence of the researcher on findings, despite previously discussed attempts to limit and reflect on such influence. Furthermore, the researcher's position as a white, female mental health professional may have been a barrier to participants feeling able or willing to present some aspects of their identity. This was alluded to by participants at times, (e.g., Jack: "If I'm talking to an adult, I know had to adjust myself. I'll talk more formally, or whatever it is that it may be necessary I don't know. It depends who is sitting in front of me"; "Rather than I could have been placed with any, no disrespect, it could have been a white family. Which is not really relatable to $\mathrm{me}^{\prime \prime}$ ).

\subsection{Implications}

LAC and care-leavers' identities are often labelled as pathological. Care-leavers have higher rates of psychiatric diagnosis and are more likely to have contact with the criminal justice system than the general population [54]. These rates are even higher for care-leavers from BAME backgrounds [18]. This study offers an alternative construction of BAME care-leaver identity as resilient and adaptive. Moreover, mainstream understandings of identity tend to view so-called pathological identity in LAC as entrenched and chronic; unlikely to shift significantly even with mental health service input [55]. This study instead provides a hopeful picture of aspiration and personal growth. Tarren-Sweeney [56] points out that prolonged mental health service engagement may increase already profound feelings of difference and shame in care-leavers. The findings around the relationship with the recruitment charity, however, suggest that the development of long-term, positive relationships with some services can be reparative, and may provide a secure base from which to grow and develop connections. Although not a mental health service, the charity was associated with the care-leaver label, suggesting it is not the label, or service involvement that is in-itself pathologising. Further research into the experience of mental health service and engagement for LAC, and their views on how to improve it, may elucidate this. Mental health services, particularly adult services, can lack an understanding of developmental trauma, and therefore the adaptive function many 'treatment behaviours' serve. A trauma-informed approach would acknowledge the adaptiveness of current coping strategies while supporting service users to find new ways of self-regulation and relating to others. Therapeutic approaches that facilitate re-storying adverse experiences may support positive identity development.

This research has implications for the way resilience is understood. Resilience is a commonly used, but rarely defined, term in LAC teams. It is generally thought to relate to an individual's 'relative resistance to psychosocial risk experiences' [57]. This definition could be problematic in light of the results of this study. What is actually 'relative resistance' in care-leavers, for example the adaptive survival mechanisms identified in this study, may be subject to pathologising discourse in mental health services and mainstream media. While strengths-based approaches may empower and de-stigmatise care-leavers [58], further research is needed to fully explore the concept of resilience as it relates to this group. South, Jones, Creith and Simonds [59] found that foster carers associated resilience with LAC's ability to shut off and distance themselves from distress. This conflation of self-reliance and resilience may feed into relational dynamics described by participants in this study, who felt foster carers were unwilling to provide emotional support, and therefore withdrew further into self-reliance and aloneness. However, it is important to acknowledge that this construction of resilience may serve as an understandable defence for foster carers faced with a child in considerable pain and distress, with little recourse to professional support themselves. This highlights the pressing need for ongoing psychological support and training for foster carers.

While many of the participants' experiences of identity development appeared to be consistent with wider literature on LAC identity, their identification with minority groups appeared to compound some of the difficulties faced by LAC. In particular, they appeared to face additional adversity, and had to navigate more complex relationships to difference and belongingness. Psychological and social interventions for this group of young people should consider these factors. It is also vital that white 
professionals and carers working with this group are able to consider the impact of their whiteness on BAME LAC's ability to open up these conversations, and take proactive steps to make it safe to do so.

Participants' determination to construct their own unique relationship with their culture was striking. While this corroborates the need for those working with LAC to be aware of and provide for LAC's need for cultural connectedness, it also highlights the individual nature of cultural identities, and therefore the need to approach this openly and without assumptions around cultural tradition. It could also be possible that this relationship with culture relates to the ambivalence and lack of belonging felt in the other aspects of care-leavers experience. Further research into how care-leavers experience their cultural identity is needed.

\section{Conclusions}

A literature search highlighted that identity development in BAME LAC is a subordinated area of research. Further, while there is considerable research literature on childhood trauma, this often focuses on its role in the development of individual psychopathology. This study adds to the limited literature and offers a unique understanding of identity development for these participants as highly adaptive within the context of their early experiences. It also emphasises the active and dynamic nature of identity. Participants actively constructed their identities in the context of their past, and developed their understanding of the past through experiences in the present. Finally, this study points to the reparative potential of positive, safe relationships for these participants, both as children and adults. Due to the dearth of research in this area, further elaboration on these findings is required.

Author Contributions: Conceptualisation, I.L., A.H. and A.C.; methodology, I.L. and A.H.; validation, I.L. and A.H.; investigation, I.L.; data collection, I.L.; formal analysis, I.L.; investigation, I.L.; writing-original draft preparation, I.L.; writing-review and editing, I.L., A.H. and A.C.; supervision, A.H. and A.C. All authors have read and agreed to the published version of the manuscript.

Funding: This research received no external funding.

Institutional Review Board Statement: The study was conducted according to the guidelines of the Declaration of Helsinki, and, and approved by the Ethics Committee of the Salomons Institute of Applied Psychology, School of Psychology and Life Sciences, Canterbury University (Approved 28th January 2018).

Informed Consent Statement: Informed consent was obtained from all participants involved in the study.

Data Availability Statement: The data presented in this study are available on request from the corresponding author. The data are not publicly available due to issues of confidentiality.

Conflicts of Interest: The authors declare no conflict of interest.

\section{References}

1. Schwartz, S.J.; Hardy, S.A.; Zamboanga, B.L.; Meca, A.; Waterman, A.S.; Picariello, S.; Luyckx, K.; Crocetti, E.; Kim, S.Y.; Brittian, A.S.; et al. Identity in young adulthood: Links with mental health and risky behavior. J. Appl. Dev. Psychol. 2015, 36, 39-52. [CrossRef]

2. Kroger, J. Identity Development: Adolescence through Adulthood; SAGE Publications: London, UK, 2007.

3. Department of Health. Framework for the Assessment of Children in Need and Their Families; Department of Health: London, UK, 2000.

4. Bowlby, J. Attachment and Loss: Attachment; Basic Books: New York, NY, USA, 1969.

5. Erikson. Identity: Youth and crisis. Arch. Gen. Psychiatry 1969, 21, 635-636. [CrossRef]

6. Marcia, J.E. Identity in adolescence. In Handbook of Adolescent Psychology; Wiley: New York, NY, USA, 1980; pp. 159-187.

7. McAdams, D.P.; McLean, K.C. Narrative Identity. Curr. Dir. Psychol. Sci. 2013, 22, 233-238. [CrossRef]

8. McLean, K.C.; Pasupathi, M.; Pals, J.L. Selves creating stories creating selves: A process model of self-development. Personal. Soc. Psychol. Rev. 2007, 11, 262-278. [CrossRef] 
9. Barn, R. Care leavers and social capital: Understanding and negotiating racial and ethnic identity. Ethn. Racial Stud. 2010, 33, 832-850. [CrossRef]

10. Arnett, J.J. Emerging Adulthood: A theory of development from the late teens through the twenties. Am. Psychol. 2000, 55, 469-480. [CrossRef]

11. Copeland, W.E.; Keeler, G.; Angold, A.; Costello, E.J. Traumatic events and posttraumatic stress in childhood. Arch. Gen. Psychiatry 2007, 64, 577-584. [CrossRef]

12. Mcmurray, I.; Connolly, H.; Preston-Shoot, M.; Wigley, V. Shards of the old looking lass: Restoring the significance of identity in promoting positive outcomes for looked-after children. Child Fam. Soc. Work 2011, 16, 210-218. [CrossRef]

13. Samuels, G.M.; Pryce, J.M. 'What doesn't kill you makes you stronger': Survivalist self-reliance as resilience and risk among young adults aging out of foster care. Child. Youth Serv. Rev. 2008, 30, 1198-1210. [CrossRef]

14. Kools, S.M. Adolescent identity development in foster care. Source Fam. Relat. 1997, 46, 263-271. [CrossRef]

15. Nurcombe-Thorne, A.; Nadesan, V.; van Breda, A.D.P. Experiences of "i" and "we" among former looked-after children in South Africa. Child Fam. Soc. Work 2018, 23, 640-648. [CrossRef]

16. Stein, M. Resilience and young people leaving care. Child Care Pract. 2008, 14, 35-44. [CrossRef]

17. Bruskas, D. Children in Foster Care: A vulnerable population at risk. J. Child Adolesc. Psychiatr. Nurs. 2008, 21, 70-77. [CrossRef]

18. Colbridge, A.K.; Hassett, A.; Sisley, E. 'Who Am I?' How female care-leavers construct and make sense of their identity. SAGE Open 2017. [CrossRef]

19. Nelson, S.C.; Syed, M.; Tran, A.G.T.T.; Hu, A.W.; Lee, R.M. Pathways to ethnic-racial identity development and psychological adjustment: The differential associations of cultural socialization by parents and peers. Dev. Psychol. 2018, 54, 2166-2180. [CrossRef] [PubMed]

20. Umaña-Taylor, A.J.; Zeiders, K.H.; Updegraff, K.A. Family ethnic socialization and ethnic identity: A family-driven, youth-driven, or reciprocal process? J. Fam. Psychol. 2013, 27, 137-146. [CrossRef]

21. Syed, M.; Juang, L.P. Ethnic identity, identity coherence, and psychological functioning: Testing basic assumptions of the developmental model. Cultur. Divers. Ethnic Minor. Psychol. 2014, 20, 176-190. [CrossRef]

22. Kirton, D. (In) Sufficient?: Ethnicity and foster care in english local authorities. Child Fam. Soc. Work 2016, 21, 492-501. [CrossRef]

23. Ince, L. Making It Alone: A Study of the Care Experiences of Young Black People; CoramBAAF: London, UK, 1998.

24. Coakley, T.M.; Gruber, K. Cultural receptivity among foster parents: Implications for quality transcultural parenting. Soc. Work Res. 2015, 39, 11-22. [CrossRef]

25. Butler-Sweet, C. 'A Healthy Black Identity' Transracial adoption, middle-class families, and racial socialization. J. Comp. Fam. Stud. 2011, 42, 193-212. [CrossRef]

26. Hughes, D.; Rodriguez, J.; Smith, E.P.; Johnson, D.J.; Stevenson, H.C.; Spicer, P. Parents' ethnic-racial socialization practices: A review of research and directions for future study. Dev. Psychol. 2006, 42, 747-770. [CrossRef] [PubMed]

27. Winter, K.; Cohen, O. Identity issues for looked after children with no knowledge of their origins: Implications for research and practice. Adopt. Foster. 2005, 29, 44-52. [CrossRef]

28. Carlsson, J.; Wängqvist, M.; Frisén, A. Identity development in the late twenties: A never ending story. Dev. Psychol. 2015, 51, 334-345. [CrossRef] [PubMed]

29. British Psychological Society. Code of Ethics and Conduct: Guidance Published by the Ethics Committee of the British Psychological Society; British Psychological Society: Leicester, UK, 2009.

30. Smith, J.A.; Osborn, M. Interpretative phenomenological analysis. In Doing Social Psychology Research; Blackwell Publishing Ltd.: Oxford, UK, 2008. [CrossRef]

31. Biggerstaff, D.; Thompson, A.R. Interpretative phenomenological analysis (IPA): A qualitative methodology of choice in healthcare research. Qual. Res. Psychol. 2008, 5, 214-224. [CrossRef]

32. Yardley, L. Dilemmas in qualitative health research. Psychol. Heal. 2000, 15, 215-228. [CrossRef]

33. Tufford, L.; Newman, P. Bracketing in qualitative bracketing in qualitative. Qual. Soc. Work 2010, 11, 80-96. [CrossRef] 
34. Spinazzola, J.; Van Der Kolk, B.; Ford, J.D. When nowhere is safe: Interpersonal trauma and attachment adversity as antecedents of posttraumatic stress disorder and developmental trauma disorder. J. Trauma Stress 2018, 31, 631-642. [CrossRef] [PubMed]

35. McCormack, L.; Issaakidis, G.L. Complex trauma in childhood; psychological growth in adulthood: Making sense of the 'lived' experience of out-of-home-care. Traumatology 2018, 24, 131-139. [CrossRef]

36. Crenshaw, K. Mapping the margins: Intersectionality, identity politics, and violence against women of color. Stanf. Law Rev. 1991, 43. [CrossRef]

37. Schwartz, S.J.; Unger, J.B. Biculturalism and context: What is biculturalism, and when is it adaptive? Hum. Dev. 2010, 53, 26-32. [CrossRef]

38. Freud, S. An outline of psycho-analysis. In The Standard Edition of the Complete Psychological Works of Sigmund Freud, Volume XXIII (1937-1939): Moses and Monotheism, An Outline of Psycho-Analysis and Other Works; The Hogan Press: London, UK, 1938.

39. Heller, L.; LaPierre, A. Healing Developmental Trauma; North Atlantic Books: Berkley, CA, USA, 2012.

40. Gergen, K.J. Social construction and the transformation of identity politics. In End of Knowing: A New Developmental Way of Learning; Newman, F., Holzman, L., Eds.; Routledge: New York, NY, USA, 1999.

41. Lemma, A. Introduction to the Practice of Psychoanalytic Psychotherapy; Wiley and Sons: Chichester, UK, 2008. [CrossRef]

42. Freyd, J.J. Betrayal trauma: Traumatic amnesia as an adaptive response to childhood abuse. Ethics Behav. 1994, 4, 307-329. [CrossRef]

43. Baumeister, R.F.; Leary, M.R. The need to belong: Desire for interpersonal attachments as a fundamental human motivation. Psychol. Bull. 1995, 117, 497-529. [CrossRef] [PubMed]

44. Maslow, A. Toward a Psychology of Being, 2nd ed.; Wiley: New York, NY, USA, 1968.

45. Golding, K.S. Nurturing attachments: Supporting children who are fostered or adopted. In Nurturing Attachments: Supporting Children who are Fostered or Adopted; Jessica Kingsley: Philadelphia, PA, USA, 2008.

46. Pietkiewicz, I.; Smith, J.A. A practical guide to using Interpretative Phenomenological Analysis in qualitative research psychology. Psychol. J. 2014, 20,7-14.

47. Smith, J.A.; Flowers, P.; Larkin, M. Interpretative Phenomenological Analysis: Theory, Method and Research; SAGE Publications: London, UK, 2009.

48. Guest, G.; Bunce, A.; Johnson, L. How many interviews are enough?: An experiment with data saturation and variability. Field Methods 2006, 18, 59-82. [CrossRef]

49. Marshall, B.; Cardon, P.; Poddar, A.; Fontenot, R. Does sample size matter in qualitative research?: A review of qualitative interviews in IS research. J. Comput. Inf. Syst. 2013, 54, 11-22. [CrossRef]

50. Mason, M. Sample size and saturation in PHD studies using qualitative interviews. Forum Qual. Soc. Res. 2010, 11, 1-20.

51. Starks, H.; Trinidad, S.B. Choose Your Method-A Comparison of Phenomenology, Discourse Analysis, and Grounded Theory. Qual. Health Res. 2007, 17, 1372-1380. [CrossRef]

52. McDonald, N.; Schoenebeck, S.; Forte, A. Reliability and Inter-rater Reliability in Qualitative Research: Norms and Guidelines for CSCW and HCI Practice. Proc. ACM Hum. Comput. Interact. 2019, 3, 1-23. [CrossRef]

53. Yardley, L. Demonstrating validity in qualitative psychology. In Qualitative Psychology: A Practical Guide to Research Methods; Smith, J., Ed.; SAGE Publications: London, UK, 2008; pp. 235-251.

54. Robinson, O.C. Sampling in interview-based qualitative research: A theoretical and practical guide. Qual. Res. Psychol. 2014, 11, 25-41. [CrossRef]

55. Tarren-Sweeney, M. It's time to re-think mental health services for children in care, and those adopted from care. Clin. Child Psychol. Psychiatry 2010, 15, 613-626. [CrossRef]

56. Schmeck, K.; Schlüter-Müller, S.; Foelsch, P.A.; Doering, S. The Role of Identity in the DSM-5 Classification of Personality Disorders. Child Adolesc. Psychiatry Mental Health 2013, 7, 39. [CrossRef] [PubMed]

57. Rutter, M. Psychological resilience and protective mechanisms. In Risks and Protective Factors in the Development of Psychopathology; Cambridge University Press: Cambridge, UK, 1990.

58. Murray, S.; Goddard, J. Life after growing up in care: Informing policy and practice through research. Aust. Soc. Work. 2014, 67, 102-117. [CrossRef] 
59. South, R.; Jones, F.W.; Creith, E.; Simonds, L.M. Understanding the concept of resilience in relation to looked after children: A delphi survey of perceptions from education, social care and foster care. Clin. Child Psychol. Psychiatry 2015, 21, 178-192. [CrossRef] [PubMed]

Publisher's Note: MDPI stays neutral with regard to jurisdictional claims in published maps and institutional affiliations.

(C) 2021 by the authors. Licensee MDPI, Basel, Switzerland. This article is an open access article distributed under the terms and conditions of the Creative Commons Attribution (CC BY) license (http://creativecommons.org/licenses/by/4.0/). 